Computational Linguistics and Intellectual Technologies:

Proceedings of the International Conference "Dialogue 2020"

Moscow, June 17-20, 2020

\title{
REFERENTIAL PHENOMENA IN SPEAKER'S KINETIC CHANNELS
}

\author{
Budennaya E. V. (jane.sdrv@gmail.com) \\ Higher School of Economics / Institute of Linguistics, RAS, \\ Moscow, Russia
}

Evdokimova A. A. (arochka@gmail.com)

Institute of Linguistics, RAS, Moscow, Russia

Nikolaeva Ju. V. (julianikk@gmail.com)

Lomonosov Moscow State University, Moscow, Russia

Sukhova N. V. (sukhova.natalya@gmail.com)

National University of Science and Technology MISiS, Moscow, Russia

The article addresses the relation of referential expressions and co-occurring kinetic phenomena (hand and head gestures) on the material of the RUPEX multimodal corpus. The results reflect significant differences in how individual movements and gestures are aligned with two major types of reference (full NPs vs. reduced expressions). It was initially assumed that full NPs are more often accompanied by a gesture. Our data support this hypothesis not only through the material of hand gestures, but also through head movements. Moreover, full NPs are more likely to be accompanied by downward movements in both manual and cephalic channels, as well as by metadiscourse gestures, in comparison to reduced referential units (personal and demonstrative pronouns). In addition, pronouns are more likely to be aligned with pointing hand gestures and zero reference is often accompanied by descriptive hand gestures. However, the kinetic behavior of the interlocutors is determined by a variety of factors, including the topic of the conversation, which predisposes to certain types of gestures and the relative position of the interlocutors.

Key words: reference, referential choice, hand gestures, head movements, multimodal communication, RUPEX

DOI: $10.28995 / 2075-7182-2020-19-133-146$ 


\section{Introduction. Referential choice and related phenomena}

Referential choice, or the process of selecting a linguistic expression for a specific referent, is a challenging task in linguistics. Factors related to referential choice, such as discourse phenomena (linear and referential distance between the anaphor and its antecedent, the referent's status as protagonist), grammatical categories (i.e. animacy, gender, grammatical role), as well as typological parameters of the language as a whole (i.e. pro-drop properties), have been actively explored since the last third of the 20th century [Givón 1983]; [Gundel et al. 1993]; [Kibrik et al. 2016]; [Hint et al. 2020]. However, the exact list of factors determining referential choice remains open.

In this regard, nonverbal communication holds promise of potential related phenomena. Compared with linguistic data, non-verbal factors of referential choice have been less studied and mostly in the context of hand gestures [Levy, Fowler 2000]; [Gullberg 2006]; [Debreslioska et al. 2013]. This article considers the issue in a wider framework of Russian multichannel communication, namely in the context of head movements (cephalic channel) and hand gestures (manual channel). To date, referential mechanisms in the Russian speaker's kinetic channels have been mainly studied in the limited context of manual gestures [Grishina 2017: 78-80]. Head movements were sometimes discussed as an additional phenomenon [ibid: 156-158], but no systemic studies of both channels within the referential context were done thus far.

The work is based on the RUPEX multichannel corpus ("Russian Pear Chats and Stories", see the project website www.multidiscourse.ru and [Kibrik 2018] for detail). For the pilot study, session \#22 was selected with a total duration of approximately 54 minutes. The session consists of three videos recording a group of interlocutors with a fixed role for each (the Narrator, the Commentator and the Reteller ${ }^{1}$ ). It forms a part of a demo subcorpus annotated for four kinetic communication channels (vocal, oculomotor, manual and cephalic), as well as for referential units.

The article is structured as follows. Section 2 discusses referential expressions in the RUPEX and what is already known about their interaction with nonverbal units of communication. Section 3 describes principles for manual and cephalic annotation. Sections 4 and 5 are devoted to the results of comparing head and hand movements with aligned referential expressions.

\section{Referential units in the context of verbal and non-verbal factors}

The RUPEX referential mark-up includes all language expressions with a specific reference. Among them, two main types of units are distinguished-anaphoric and deictic. This article is devoted to anaphoric reference. For RUPEX deictic expressions and their relation to the speaker's communicative role, see [Budennaya 2019: 132].

Anaphoric units are linguistic expressions whose interpretation depends on the previous context. Thus, the same referent can be marked by a full NP (mal'čik uezžaet 'the boy leaves'), a personal pronoun (on uezžaet 'he leaves'), a demonstrative pronoun

1 Hereinafter N, C and R, respectively. 
(tot uezžaet 'that [one] leaves'), a definite pronoun ('vse uezžajut' everybody leaves), a zero $\left(\varnothing_{\text {pro }}\right.$ uezžaet '[(s)he] leaves'), and so forth. Pronominal and zeroexpressions are combined into a more general type of reduced reference [Kibrik 2011]. It is opposed to full reference which is marked by full NPs acting as antecedents for subsequent anaphoric units: $A$ [tovarišč naverhu $]_{i},[o n]_{i}$ prodolzhaet sobirat' gruši $i\left[\varnothing_{\text {pro }}\right]_{i}$ ničego ne vidit 'And [the guy $]_{\mathrm{i}}$ above, $[\text { he }]_{\mathrm{i}}$ keeps on picking pears and does not see anything'. Both full and reduced referential expressions are marked in the RUPEX with ELAN software (https://tla.mpi.nl/tools/tla-tools/elan/), with zero units being attributed to the word explicitly expressed immediately thereafter (see [Budennaya 2019] for more details on the referential mark-up).

Traditionally reduced (or attenuated) anaphoric expressions code highly accessible and identifiable entities [Givón 1983]; [Ariel 1990]; [Gundel et al. 1993]. In contrast, full NPs are prototypically chosen for new and less accessible referents. Both full and reduced reference correlate with various grammatical, semantic and discourse factors, although their role varies from language to language [Kibrik et al. 2016]; [Hint et al. 2020]. From the non-verbal perspective, full NPs are more often accompanied by a gesture than reduced expressions [Levy, Fowler 2000], which holds true not only for gestures in general, but for their selected functional types as well (see, for example, [Azar et. A1. 2019] on pointing gestures). In this study, Sections 3 and 4 will provide data on how the direction of a gesture, the referent's position in the speaker's gestural space, and the type of referential expression interact with each other in RUPEX cephalic and manual channels.

\section{Methodology}

\subsection{Principles of cephalic and manual annotation}

To compare verbal and non-verbal expressions, a unified method of annotating these phenomena in kinetic (cephalic and manual) channels was used. Within this method, all gestures were coded for directions and their phases.

Cephalic movements were tagged in accordance with the direction (down-up, right-left, forward-backward) and with the type of action (tilt, turn, slide, rotation, etc.). Since head movements are often superimposed, they were marked in three layers for accuracy: Movement A, Movement B and Displacement (the latter is not covered in the article). All communication movements performed by the neck muscles independently of other kinetic channels fell into Movement A. All movements produced under the influence of one of the other channels, as well as echo movements and adaptors, were tagged under Movement B [Kibrik, Fedorova 2020], see Figure 1 for illustration.

When analyzing the relationship between the direction of movements and referential phenomena, the type of referential expression was marked along with the cases when the onset of the cephalic movement was ahead or lagged behind the concomitant referential expression, as shown in Figure 2. 

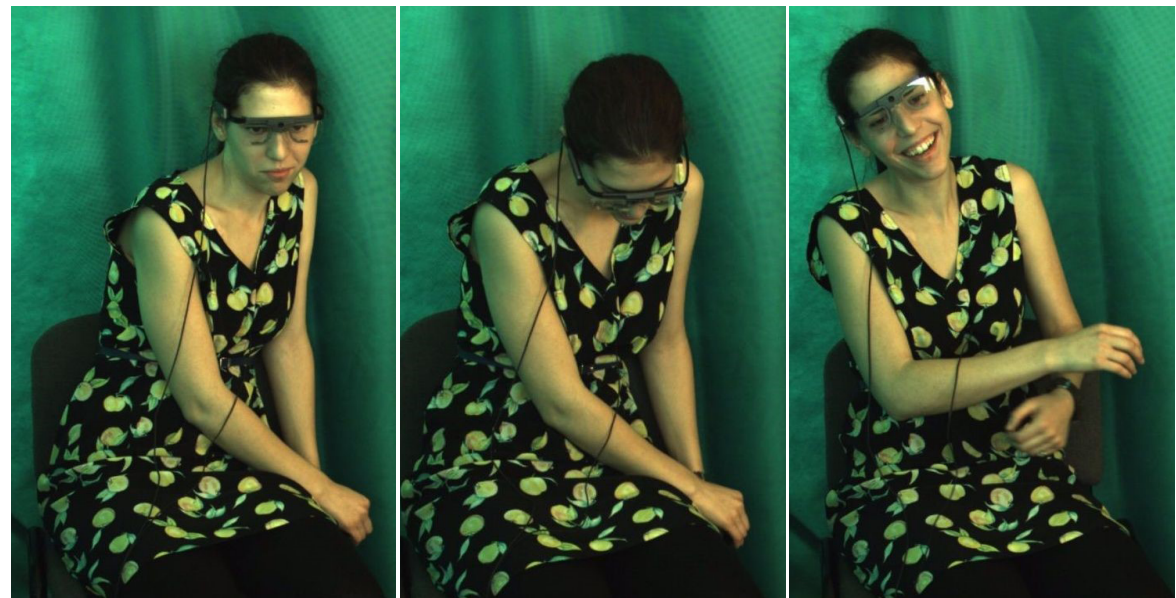

Fig. 1. Sequence of Movements B

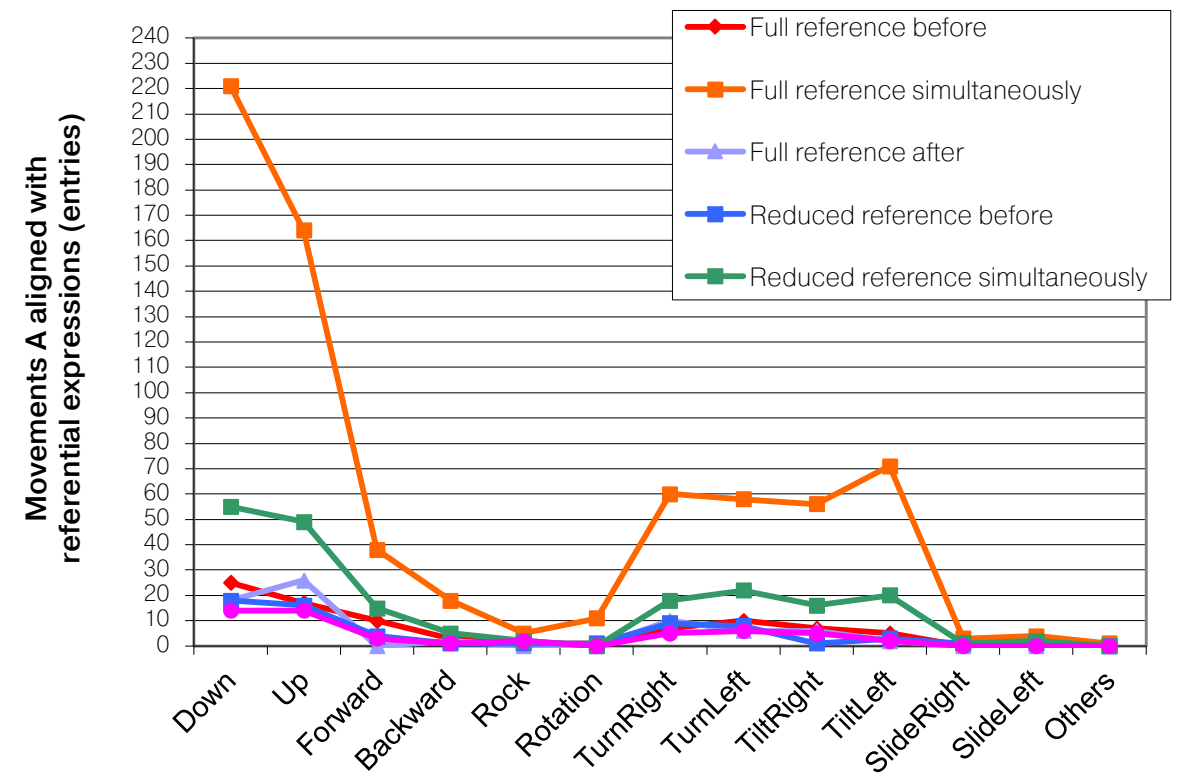

Fig. 2. Position of head movements (type A), according to concomitant referential units

The principles of the RUPEX's manual annotation are detailed in [Litvinenko et al. 2018]. In this study, we examined only the hand movements that were marked as gestures. Each movement was coded for direction (up/down, right/left, to the center/from the center). For all movements aligned with referential expressions, both reference and functional type of gesture under discussion (see Section 3.2) were specified. 


\subsection{Types of cephalic and manual gestures}

The functional types of hand gestures were approached as outlined in [Litvinenko et al. 2018], but pragmatic gestures were defined as a separate category, as were depictive, pointing and rhythmic gestures. This classification is based on functional grounds and can thus be applied to cephalic movements with some reservations. Since the main part of our material consists of monologue fragments (narration and retelling), only rare examples of regulatory hand movements marking the participants' interaction and conversational turn-taking were found. At the same time, head movements, if there are more than two interlocutors, often reflect how participants interact with each other and show to whom or to what the gesticulating person is paying attention. Such movements are marked with a higher amplitude and are clearly interpreted by the addressees. In this regard, the category of regulatory gestures was added for head movements [Ekman, Friesen 1969]. Some head gestures performed several functions, all such cases were considered separately.

\section{Types of movement and reference}

\subsection{Direction of movement and type of reference in the cephalic channel}

In total, 942 head movements of Movement A were aligned with referential expressions. The majority of them corresponded to downward and upward movements. Out of the three participants, only $\mathrm{C}$ had an equal distribution of the two types of movements, while $\mathrm{R}$ had a clear predominance of downward movements $(30 \%$ and $17 \%$ respectively). The distribution is shown in Figure 3.

When compared with other parameters, a statistically significant relationship was found between the type of referential expression and the amplitude of the movement aligned. Thus, in about a half of full NPs, the speaker's head moved with a medium amplitude; in about a third, with a low amplitude, and only in about $17 \%$ of cases-with a high amplitude $(\chi$-square, $\mathrm{p}$-value $<0.01)$. On reduced expressions, the speaker produced movements of different amplitudes with an equal frequency (see Figure 4), but compared to full NPs, they moved their head significantly more often with a medium amplitude and significantly less often with a high one ( $\chi$-square, $p$-value $<0.01$ ).

The above data indicate a significant correlation between downward movements and concomitant referential expressions (Pearson correlation coefficient $=0.979$ ). That is, for all types of amplitude, downward movement A occurs more often on full NPs, rather than on reduced expressions ( $\chi$-square, $p$-value $<0.01$; for illustration see Figure 5). Consequently, the movement A pattern, with the amplitude taken into account, allows one to predict the concomitant referential expression.

In Movement B type, 776 units were aligned with referential expressions. Their distribution is shown below (Figure 6).

Based on these data, we can assume that movements B are not affected by the type of concomitant referential expression. This provides additional evidence for movements B to be placed in a separate category. 


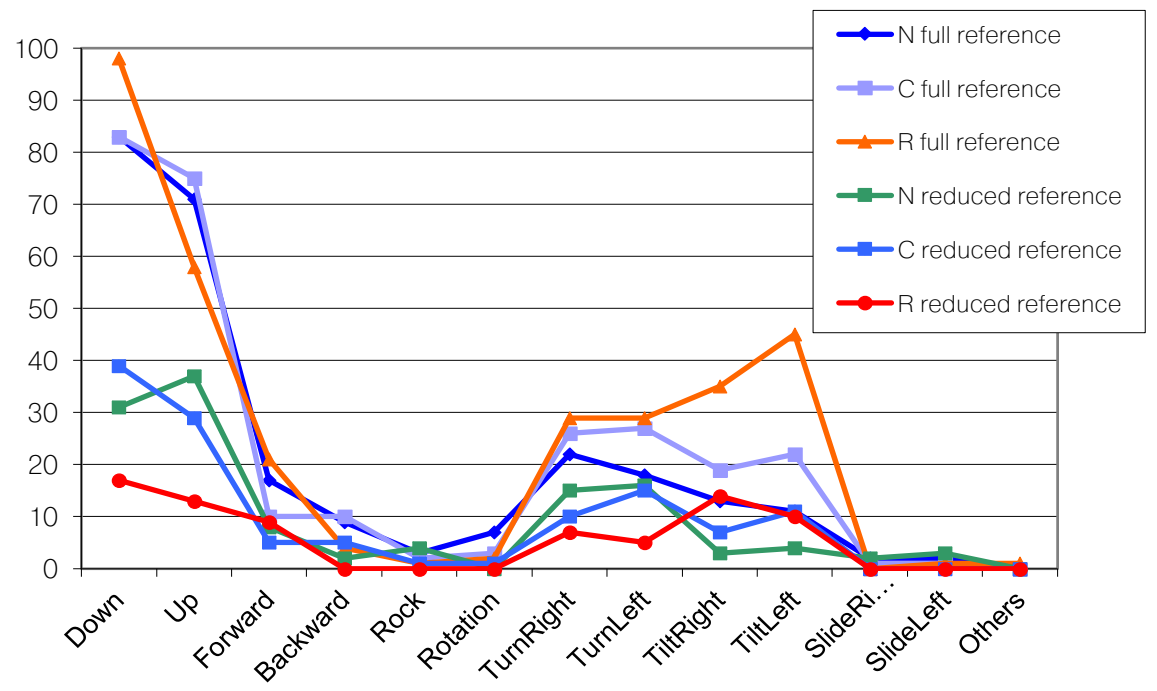

Fig. 3. Distribution of head movements (type A, \%) among N/C/R referential expressions

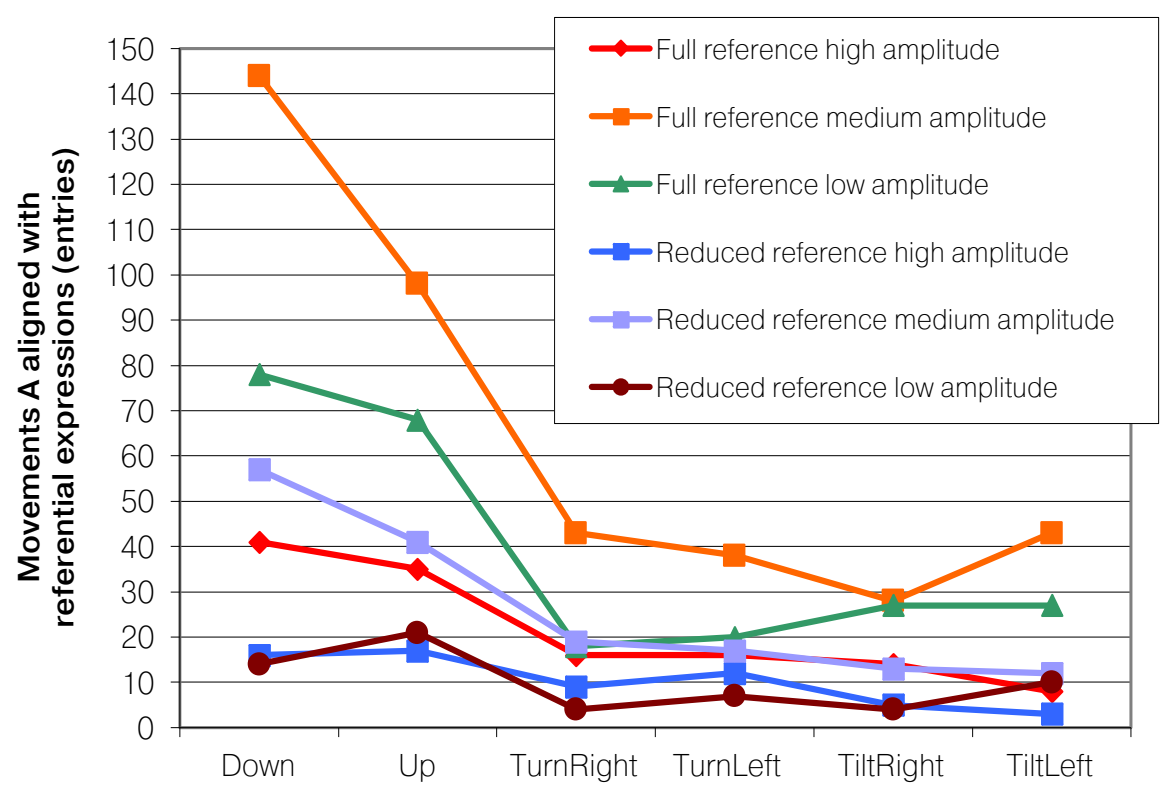

Fig. 4. Amplitude of head Movement $A$ in relation to $\mathrm{N} / \mathrm{C} / \mathrm{R}$ referential expressions 

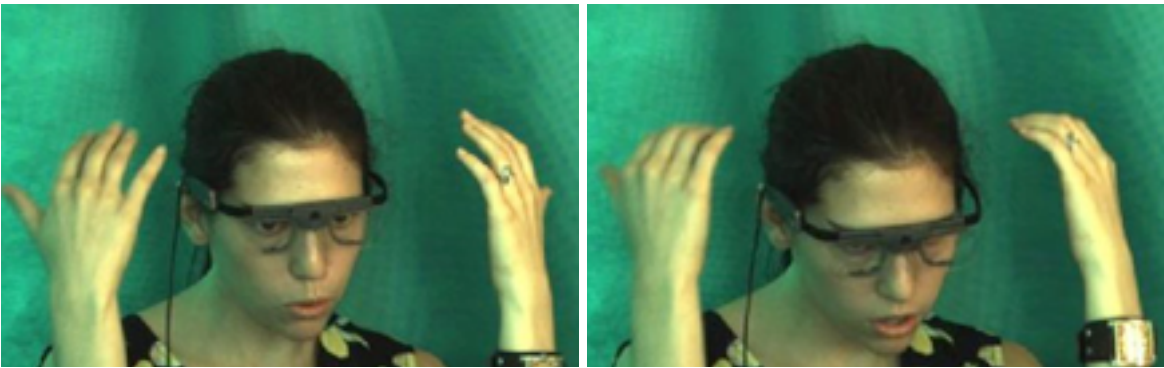

Fig. 5 The realization of a depictive head gesture represented by a downward movement (Down) with a high amplitude on full NP mnogo takih 'there are many such...' The pictures show the head from the position forward moving down simultaneously with the hands moving up in a semicircle.

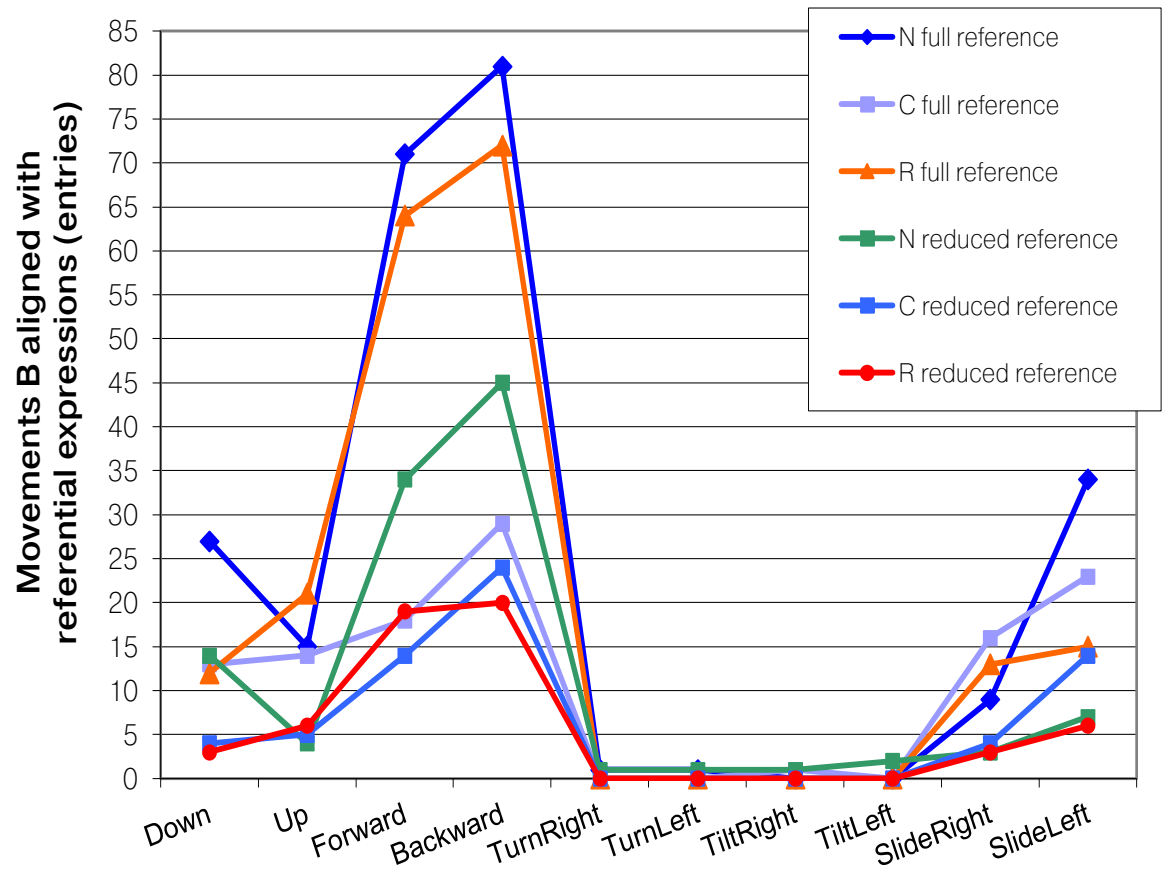

Fig. 6. Distribution of head movements (type B) in relation to referential expressions 


\subsection{Direction of movements and reference in the manual channel}

A total of 894 hand movements was aligned with referential expressions. Their relation to the hand's direction is shown in Figure 7.

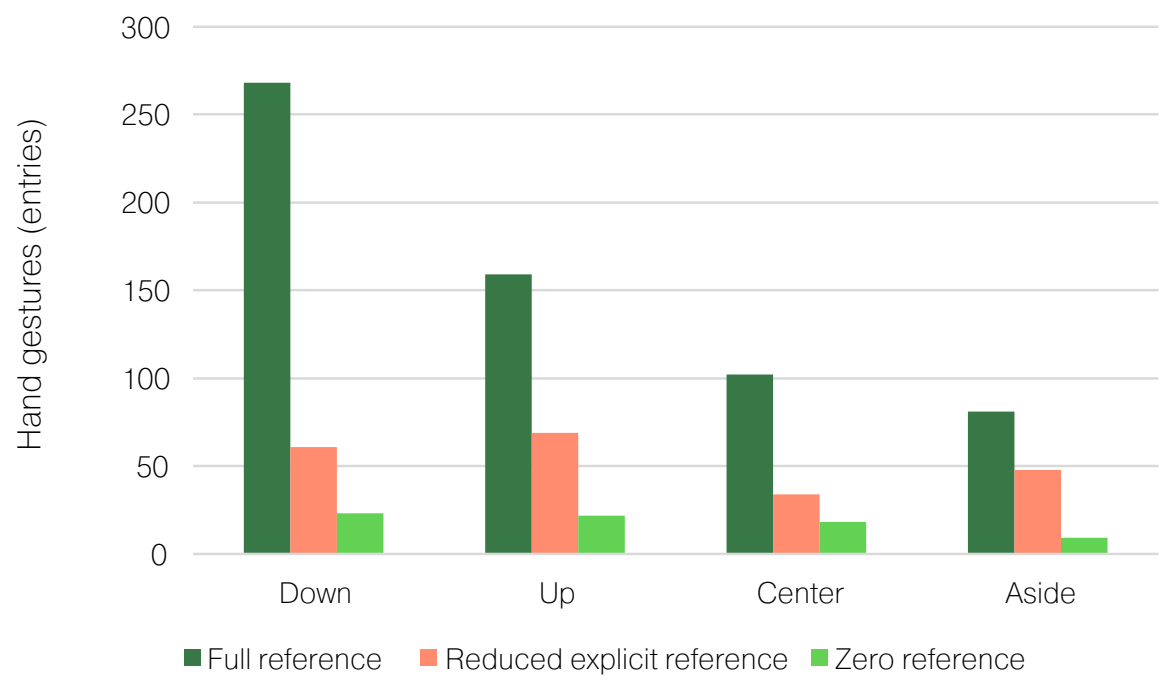

Fig. 7. Hand gesture direction within differents types of reference $(X$-square, $p<0.01)$

According to our data, downward movements were produced more often than others but differed in terms of concomitant referential expressions. On full NPs, the hand was likely to go downward, as opposed to with reduced pronominal expressions, where the same direction was the least expected. In addition, zero forms were more often accompanied by movements to the center.

\section{Functional types of gestures and reference}

\subsection{Cephalic gestures and reference}

The functional types of head gestures differ from hand gestures in many ways. Although head gestures' phases can be identified similarly to their hand counterparts (i. e., preparation, stroke, retraction [Litvinenko et al. 2018]), they may fall under different functional types. For ease of comparison, only those types of head gestures which could also be distinguished in the manual channel were considered, cf. Figure 8 and 9. 


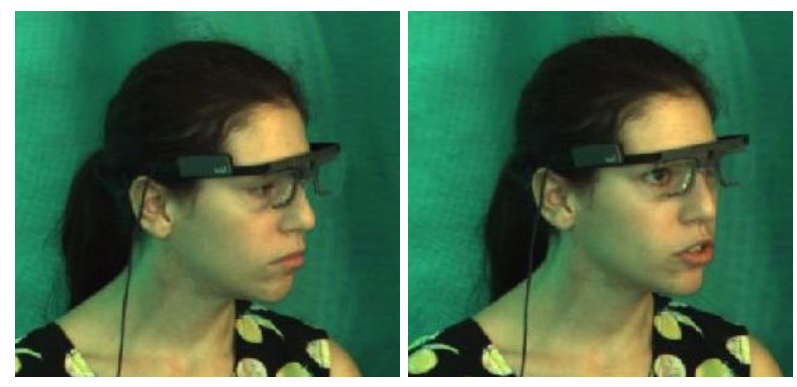

Fig. 8. The realization of a regulatory head gesture (TurnRight) aligned with the full NP malčikam 'to the boys'. The narrator keeps her head in the position from which it turns right as she utters the phrase.

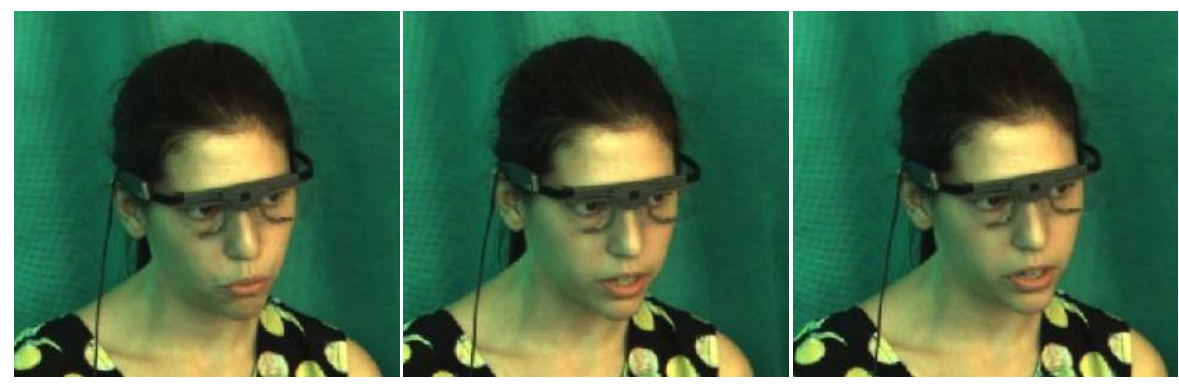

Fig. 9. The realization of a depictive head gesture (Nod2) aligned with the a zero subject expression followed by the predicate $\varnothing$ vylezaet '[he] crawls out'. The gesture path illustrates how the character crawls out from the fallen bike.

Given that, it was found that pragmatic and depictive head gestures were accompanied more frequently by full NPs $(\chi$-square, $p$-value $=0.002$ ).

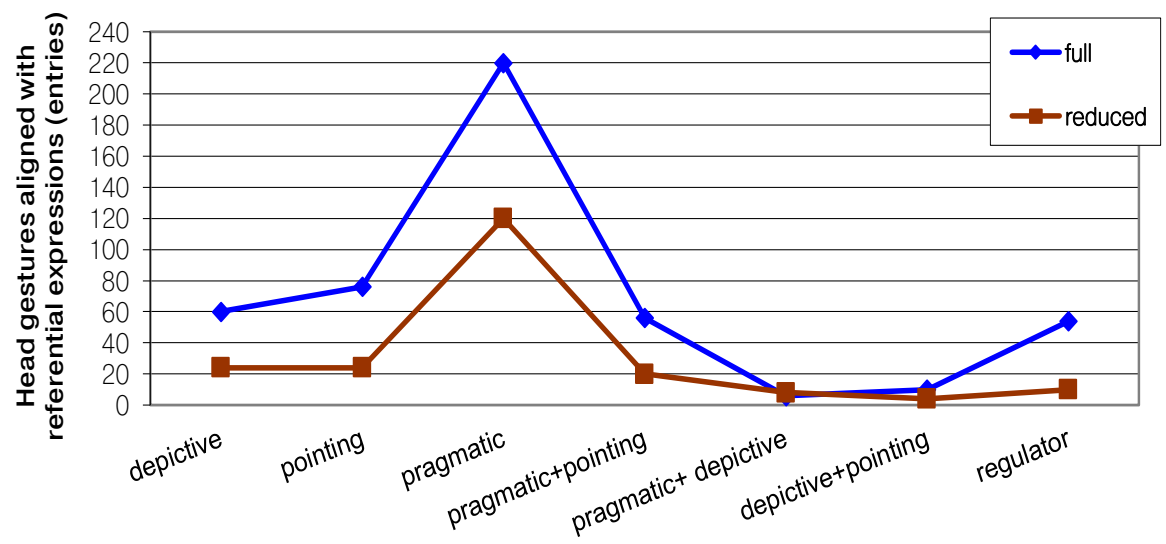

Fig. 10. Distribution of head gestures among referential expressions (22N) 
Figure 10 supports the hypothesis that a person gesticulates more often on full NPs than on reduced units [Levy, Fowler 2000]; [Debreslioska et al. 2013] and confirms it for the cephalic channel, see Figure 11 for illustration.
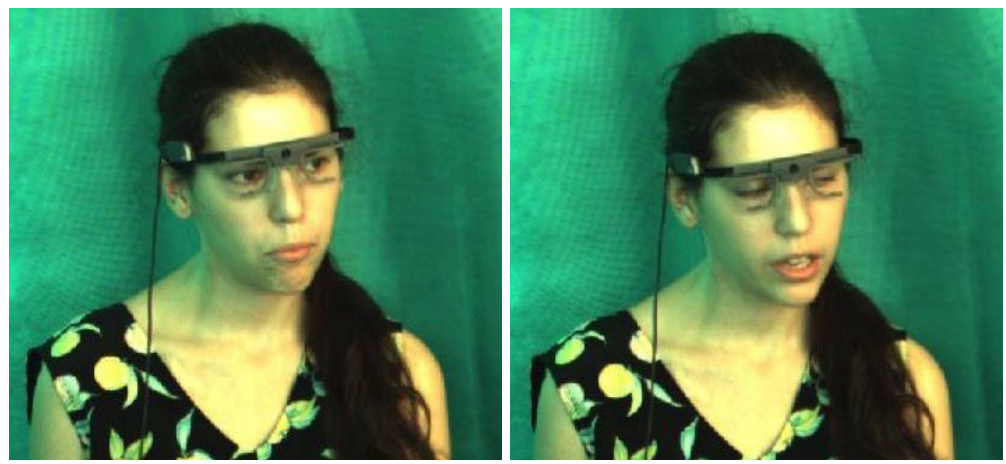

Figure 11. The realization of a pragmatic head gesture (Down) aligned with the full NP pole 'field'.

\subsection{Manual gestures and reference}

In total, 425 referential expressions were accompanied hand gestures. There were no entries in this sample where zero reference coincided with a rhythmic gesture. Since the overall number of rhythmic gestures (beats) was small (38 cases), it was decided to combine them with pragmatic gestures, based on the fact that rhythmic gestures often perform metadiscourse functions [Krahmer, Swerts 2007]. The overall distribution of gestures, according to the functional type and to the type of concomitant referential expression, is presented in Fig. 12 (a, b).

According to the above data, depictive gestures are more likely to occur on predicates with zero reference $(\chi$-square, $p$-value $<0.005)$ and less likely to occur on explicit reduced referential expressions (personal, rare demonstrative and determinative pronouns). Pointing gestures, on the contrary, are less likely to be aligned with zero reference, but are often accompanied by explicit referential expressions, primarily by personal pronouns (cf. Figure 13 and 14). 


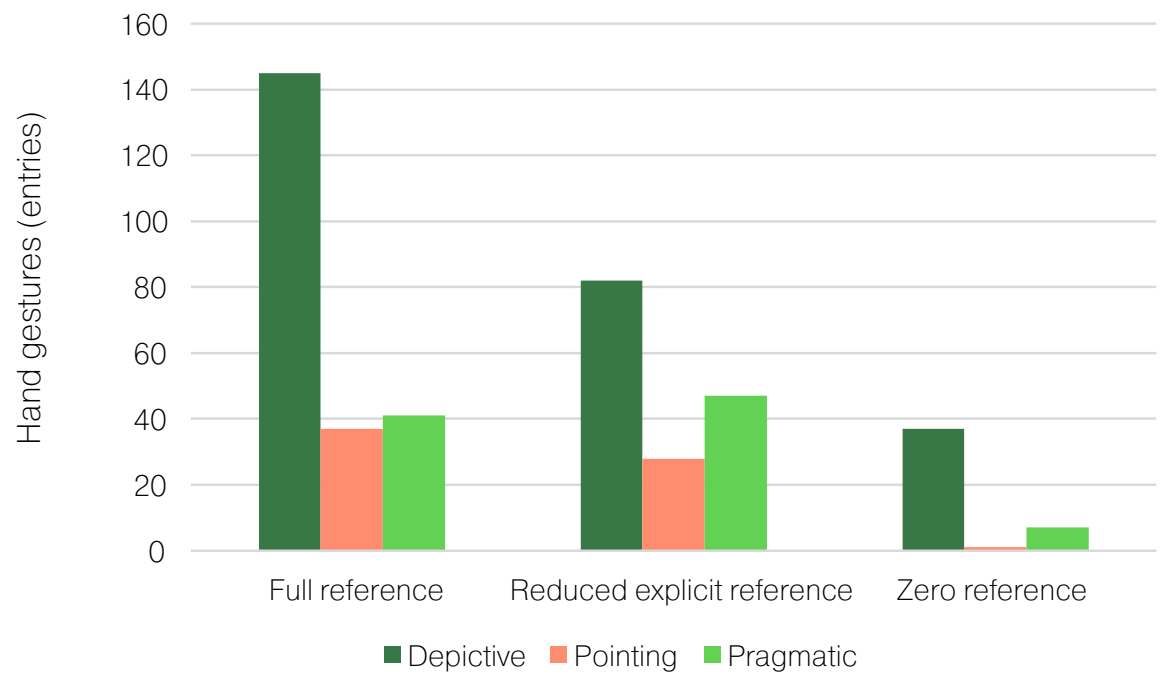

Fig. 12a. Functional types of hand gestures and types of reference (raw numbers)

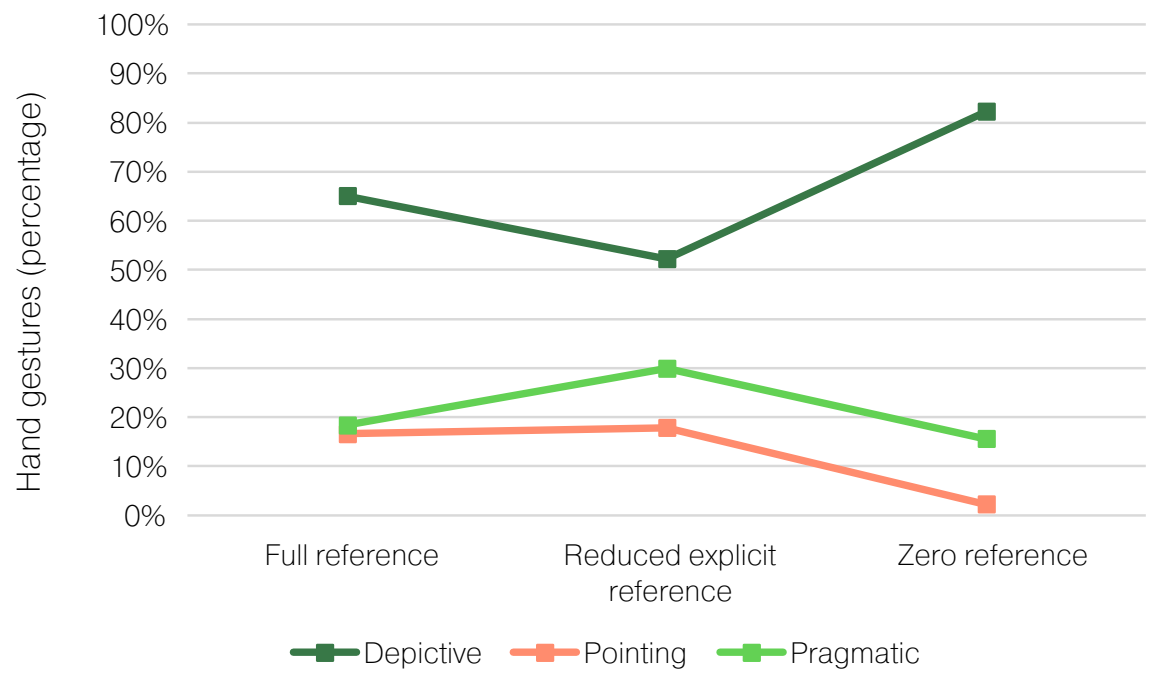

Fig. 12b. Functional types of hand gestures and types of reference (percentage) 

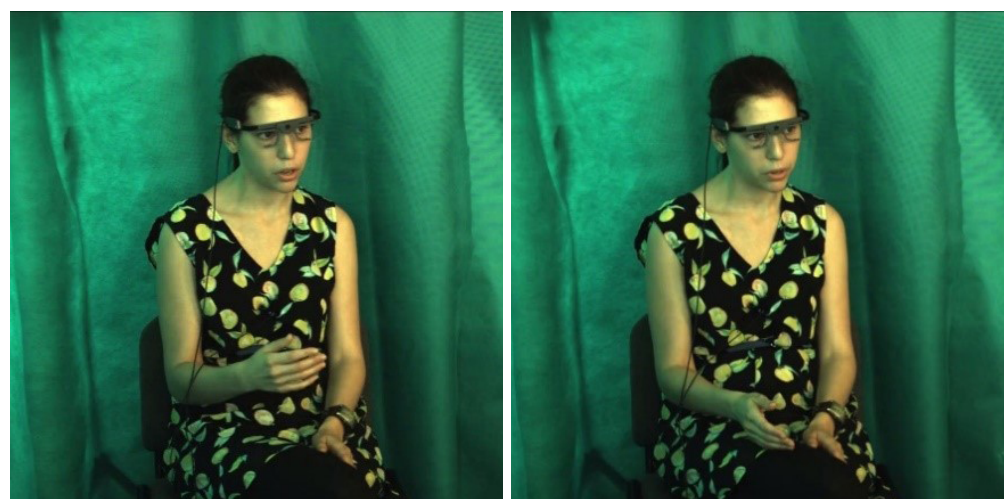

Fig. 13. The realization of a depictive hand gesture with a downward direction which accompanies zero reference. The hand gesture occurs on the phrase pomogajut emu podnyatsya 'they help him to stand up'. The narrator moves her right hand in a semicircle and then downward, even though the semantics of the word "stand up" suggests the movement "up".
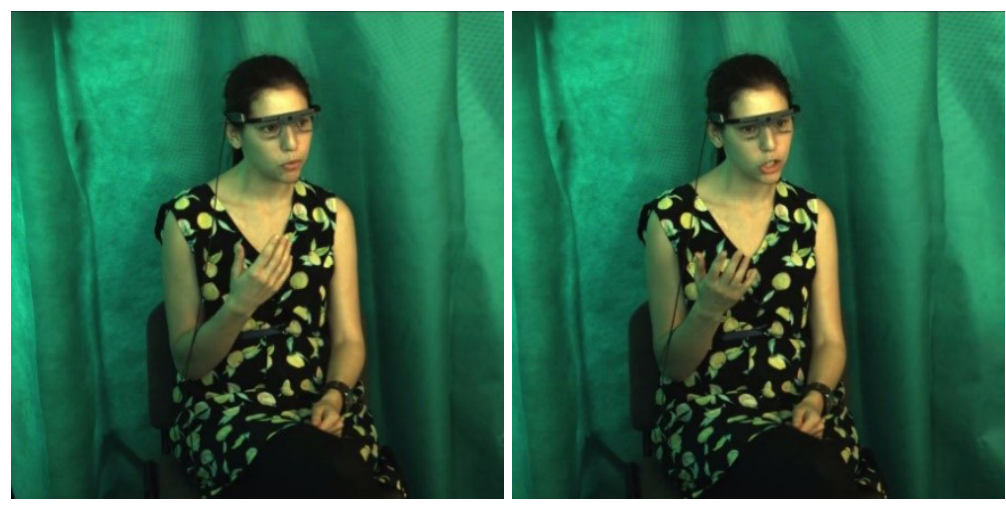

Fig. 14. The realization of a pointing hand gesture which accompanies the personal pronoun. On the phrase čto on vot možet ne zametit' čto-to 'that he can somehow miss something' the narrator points to her face first, then she does several short movements with her hand away to the right.

\section{Discussion}

As the data in Section 5 show, manual and cephalic gestures are combined in different ways with referential expressions.

There can be several explanations for the fact that zero expressions are more likely to be accompanied by depictive hand gestures. As shown in [Nikolaeva 2004], depictive gestures more often illustrate the foreground of the discourse and are often 
aligned with the most dynamic events of the story's mainline. It is expected that such a description will relate to the actions of the protagonist, who is highly activated and therefore often not explicitly expressed. In addition, depictive gestures more often align with actions, and thus correlate with predicates to which zero expressions are attributed in the corpus. The data presented in Figure 10 is consistent with the observation about the time coordination between the depictive gesture and the action performed by the protagonist [ibid]. We can assume that the detected correlation between depictive gestures and reduced referential expressions is a superficial phenomenon driven by internal factors, such as the referent's status as protagonist and topic continuity, which affect both the functional type of gesture and the type of concomitant referential expression.

Reduced reference is more likely to occur in situations of several competing antecedents. Their distinction is associated with the referent's position in the gestural space around the speaker, and thus the transition from one referent to another is accompanied by gestures in the horizontal plane. The least obvious is why zero referents are accompanied by movements of the hand or hands toward the center. Probably this tendency can be explained by specific stimulus material: the actions often mentioned are those that can be illustrated with upward gestures (for example, sadovnik podnimaetsya po lestnice 'the gardener goes up the stairs').

In addition, it was found that full NPs are more often accompanied not only by hand movements but also by cephalic gestures, compared to reduced expressions. Moreover, in the cephalic channel full NPs are more likely to be aligned with downward movements A and with pragmatic gestures. For Movement B, no correlation with referential expressions was detected but two directions were most often used: forward-backward and slide to the left. This indicates the adjustment of the gestural component of the interlocutors to each other and the independence of Movement B from reference. Other features can be explained by individual gestural portraits of the participants.

\section{References}

1. Ariel M. (1990), Accessing noun-phrase antecedents, Routledge, London.

2. Azar Z., Backus A., Özyürek A. (2019), General and language-specific factors influence reference tracking in speech and gesture in discourse, Discourse Processes, 56 (7), pp. 553-574.

3. Ekman P., Friesen W. V. (1969), The repertoire of nonverbal behavior: categories, origins, usage and coding, Semiotica, 1, pp. 49-98.

4. Budennaya E. V. (2019), Referential choice in multimodal communication, Computational Linguistics and Intellectual Technologies [Komp'juternaja lingvistika i intellektual'nye tehnologii. Po materialam ezhegodnoj Mezhdunarodnoj konferencii "Dialog"], Moscow, 18 (25), pp. 125-136.

5. Debreslioska S., Özürek A., Gullberg M., Perniss P. (2013), Gestural viewpoint signals referent accessibility, Discourse Processes, 50 (7), pp. 431-456.

6. Givón T. (1983), Topic continuity in discourse: Quantified cross-language studies, Benjamins, Amsterdam. 
7. Gullberg M. (2006), Handling discourse: gestures, reference, tracking, and communication strategies in early L2, Language Learning, 56, pp. 155-196.

8. Grishina E. A. (2017), Russian gesticulation from a linguistic perspective (corpus studies) [Russkaja gestikuljatsija s lingvisticheskoj tochki zrenija (korpusnyje issledovanija)], LRC Publishing House, Moscow.

9. Gundel J. K., Hedberg N., Zacharski R. (1993), Cognitive status and the form of referring expressions in discourse, Language 69 (2), pp. 274-307.

10. Hint H., Nahkola T., Pajusalu R. (2020), Pronouns as referential devices in Estonian, Finnish, and Russian, Journal of Pragmatics 155, pp. 43-63.

11. Kibrik A. A. (2011), Reference in discourse, Oxford University Press, Oxford.

12. Kibrik A. A. (2018), Russian multichannel discourse. Part II. Corpus development and avenues of research [Russkiy mul'tikanal'nyy diskurs. Chast' II. Razrabotka korpusa i napravleniya issledovaniy], Psychological Journal [Psikhologicheskiy Zhurnal], 39 (2), pp. 78-89.

13. Kibrik A. A., Khudyakova M. V., Dobrov G. B., Linnik A., Zalmanov D. A. (2016), Referential choice: predictability and its limits, Frontiers in Psychology, 7, p. 1429.

14. Kibrik A. A., Fedorova O. V. (eds.) (2020), The MCD handbook: A practical guide to annotating multichannel discourse, Moscow.

15. Krahmer E., Swerts M. (2007), The effects of visual beats on prosodic prominence: Acoustic analyses, auditory perception and visual perception, Journal of Memory and Language, 57, pp. 396-414.

16. Levy E., Fowler C. (2000), Grounding references in perception, D. McNeill (ed.), Language and gesture, Cambridge University Press, New York, pp. 215-234.

17. Litvinenko A. O., Kibrik A. A., Fedorova O. V., Nikolaeva J. V. (2018), Annotating hand movements in multichannel discourse: Gestures, adaptors and manual postures, Russian Journal of Cognitive Science, 5 (2), pp. 4-17.

18. Nikolaeva Y. V. (2004), Functional and semantic aspects of illustrative gestures in Russian spoken discourse [Funktsionalnye i semanticheskie osobennosti illyustrativnykh zhestov v ustnoy rechi (na materiale russkogo yazyka)], Voprosy Jazykoznanija [Topics in the study of language], 4, pp. 48-64. 